\title{
Return to work in prostate cancer survivors - findings from a prospective study on occupational reintegration following a cancer rehabilitation program
}

Anneke Ullrich ${ }^{1 *}$, Hilke Maria Rath ${ }^{1}$, Ullrich Otto ${ }^{2}$, Christa Kerschgens ${ }^{3}$, Martin Raida ${ }^{4}$, Christa Hagen-Aukamp ${ }^{5}$ and Corinna Bergelt ${ }^{1}$

\begin{abstract}
Background: This prospective multicentre-study aimed to analyze return to work (RTW) among prostate cancer survivors 12 months after having attended a cancer rehabilitation program and to identify risk factors for no and late RTW.
\end{abstract}

Methods: Seven hundred eleven employed prostate cancer survivors treated with radical prostatectomy completed validated self-rating questionnaires at the beginning, the end, and 12 months post rehabilitation. Disease-related data was obtained from physicians and medical records. Work status and time until RTW were assessed at 12months follow-up. Data were analyzed by univariate analyses (t-tests, chi-square-tests) and multivariate logistic regression models (OR with 95\% Cl).

Results: The RTW rate at 12-months follow-up was $87 \%$ and the median time until RTW was 56 days. Univariate analyses revealed significant group differences in baseline personal characteristics and health status, psychosocial wellbeing and work-related factors between survivors who had vs. had not returned to work. Patients' perceptions of not being able to work (OR 3.671) and feeling incapable to return to the former job (OR 3.162) were the strongest predictors for not having returned to work at 12-months follow-up. Being diagnosed with UICC tumor stage III (OR 2. 946) and patients' perceptions of not being able to work (OR 4.502) were the strongest predictors for late RTW ( $\geq$ 8 weeks).

Conclusions: A high proportion of prostate cancer survivors return to work after a cancer rehabilitation program. However, results indicate the necessity to early identify survivors with low RTW motivation and unfavorable workrelated perceptions who may benefit from intensified occupational support during cancer rehabilitation.

Keywords: Prostate cancer, Oncology, Return to work, Time until return to work, Rehabilitation, Psycho-oncology, Predictor

\footnotetext{
* Correspondence: a.ullrich@uke.de

${ }^{1}$ Department of Medical Psychology, University Medical Center

Hamburg-Eppendorf, Center for Psychosocial Medicine, Martinistrasse 52,

20246 Hamburg, Germany

Full list of author information is available at the end of the article
}

(c) The Author(s). 2018 Open Access This article is distributed under the terms of the Creative Commons Attribution 4.0 International License (http://creativecommons.org/licenses/by/4.0/), which permits unrestricted use, distribution, and reproduction in any medium, provided you give appropriate credit to the original author(s) and the source, provide a link to the Creative Commons license, and indicate if changes were made. The Creative Commons Public Domain Dedication waiver (http://creativecommons.org/publicdomain/zero/1.0/) applies to the data made available in this article, unless otherwise stated. 


\section{Background}

Return to work (RTW) is highly relevant for cancer recovery and the social reintegration of working-age cancer patients, as work provides social connections, self-esteem and independence, and helps to regain a sense of normalcy [1, 2]. Not returning to work after cancer presents a challenge for both the individual and the society as a whole $[3,4]$. An international review reporting a mean RTW rate of $63.5 \%$ indicates that approximately one third of cancer patients do not work 1 year after diagnosis [5]. As some adverse effects of not working may increase with the time passing, time until RTW is a relevant outcome of successful occupational reintegration [4]. For example, long-term sickness absence has been shown to increase the risk of early retirement [6]. A growing body of evidence suggests personal, disease- and treatment-related, psychosocial and work-related factors that may be barriers for RTW or may cause delayed RTW [4-11].

However, surprisingly little research has focused on RTW outcomes in survivors of prostate cancer, although it is the most common malignancy among men in economically developed countries [12]. In Europe, in 2012 approximately 119,000 men of working age were newly diagnosed with prostate cancer [13]. As different cancer sites are associated with varying prognosis, symptom burden and treatment procedures, RTW research should be geared to specific cancer survivor groups. Further, work should be considered as a key aspect of life and self-identity among working-age men [14-16], and studies on cancer and employment suggest gender-differences regarding various RTW outcomes [17]. In prior studies, prostate cancer survivors showed lower employment rates [7, 18], a higher probability to retire [19], longer absence from work $[11,20]$ and worse levels of work ability [21, 22] compared to men without cancer diagnosis. However, some studies indicate that prostate cancer survivors show better RTW outcomes, such as lower work disability rates [23] and the level of reduced employment participation [24], than survivors from other cancer entities.

In Germany, depending on criteria of rehabilitation need and prognosis, patients are entitled to participate in cancer rehabilitation programs following acute treatment, which are mainly provided in an inpatient setting and generally last 3 weeks [25]. According to the World Health Organization's International Classification of Functioning, Disability and Health (ICF) [26], those programs aim to help patients regaining functioning, activity and participation through multimodal treatment concepts, with standard application of occupational counseling for working-age patients. For patients of working age, costs for such programs are most commonly covered by the German Pension Insurance Agency [27].

We conducted a study in a population of employed prostate cancer survivors who participated in a cancer rehabilitation program immediately following radical prostatectomy. The purpose of our study was (1) to analyze the RTW rate and time until RTW in this patient population 12 months after having attended the rehabilitation program and (2) to identify socio-demographic, disease-specific, psychosocial and work-related factors associated with not having returned to work and late RTW at 12-months follow-up. With the second aim, we sought to detect survivors at risk for adverse RTW outcomes at an early stage of the RTW process.

\section{Methods}

\section{Study design and study population}

In this prospective multicentre-study, survivors were consecutively enrolled in four German specialized rehabilitation clinics between October 2010 and June 2012. Eligible survivors were recruited during the initial clinical consultation at the beginning of the rehabilitation program. Survivors were included if they met the following criteria:

- localized prostate cancer (no evidence of lymphogenic and distant metastasis)

- starting the rehabilitation program within 14 days after the end of acute treatment ("post-acute rehabilitation")

- working age (18-64 years)

- paid employment prior to radical prostatectomy

- written informed consent provided for study participation, data analysis and publication.

The exclusion criteria were the following:

- early retirement or having applied for a pension

- severe psychological or physical stress (physician's assessment)

- inadequate knowledge of the German language.

The study protocol was approved by the ethics committee of the General Medical Council of Hamburg (PV3547) and the department of data security of the German Pension Insurance Agency.

Patient-reported data were collected by questionnaires at the beginning, at the end, and 12 months after the end of the rehabilitation program. The first two questionnaires were handed over by the treating physicians, the follow-up questionnaire was mailed to the respondents. Disease-specific data were given by physicians and retrieved from medical records. 


\section{Rehabilitation programs}

Based on guidelines concerning cancer rehabilitation, prostate cancer survivors received a (non study-specific) comprehensive multidisciplinary medical rehabilitation program with high treatment intensity. All rehabilitation clinics were certified for provision of prostate cancer rehabilitation programs. Three clinics provided rehabilitation for patients of different cancer types and one was a clinic for urological cancers. Clinics offered inpatient and/or fulltime outpatient cancer rehabilitation, with the National Association for Rehabilitation demanding comparable therapeutic treatment and staffing of the clinic for both rehabilitation settings [28]. Both in- and outpatient rehabilitation programs include medical treatment, physical training, psychological support/therapy, social counseling as well as patient education. Categories of therapeutic treatment are constituted in the Pension Insurance's KTL classification system [29]. Actual provision of care might vary across patient groups. To collect information on rehabilitation processes in the studied cohort of prostate cancer survivors, kind and dose of treatments were derived from routine data and have been reported elsewhere [30]. Patients of both rehabilitation settings received a comparable treatment dose (approx. $12 \mathrm{~h}$ per week), but to some extent differed in the kind of treatments. Largest group differences were found in the category "sports and exercise therapy" for the benefit of outpatients and in the category "ergotherapy, occupational therapy and other functional therapies" for the benefit of inpatients. Discrepancies were due to differences regarding patients' characteristics in the in- and outpatient setting.

\section{Measurements}

\section{Variables on RTW outcomes}

Data regarding RTW rate and time until RTW were collected at 12-months follow-up. The current work status was assessed by confirmation of one of the following options: being employed part- or full-time, unemployed, disability or retirement pension. Survivors were either allocated to the group 'having returned to work' (working part- or full-time) or 'not having returned to work' (including the remaining categories) following a binary approach of RTW. Furthermore, survivors were asked to report on the exact date of their RTW following the rehabilitation program. The date of RTW was defined as time point when survivors started to work in any payed employment after the end of the rehabilitation program, independent of potential changes related to the working situation (e.g. reduced working hours, changes of working tasks or employer). Almost all survivors had returned to work without any changes of the job situation or weekly hours worked compared to the time prior to the prostate cancer diagnosis [31]. Time until
RTW (in days) was calculated by linkage of the patient-reported date of RTW to the date of discharge from the rehabilitation clinics retrieved from medical records. The sample was dichotomized at the median time until RTW (8 weeks) and each survivor was assigned to the group 'early RTW' ( $<8$ weeks) or 'late RTW' ( $\geq 8$ weeks).

\section{Potential predictor variables}

The set of potential predictors was chosen to fit the model on cancer and work as proposed by Feuerstein et al. [32] comprising seven dimensions associated with RTW outcomes: survivor's personal characteristics, health status and well-being, function, symptoms, work demands, work environment, and healthcare system. We examined a comprehensive set of factors from each dimension by mainly using validated self-rating scales (German versions). All data were obtained at the beginning of the rehabilitation program (baseline).

Survivors reported on personal characteristics (date of birth, marital status; data collection about educational level, monthly household net income and occupational position adapted from the social class index by Winkler and Stolzenberg [33]). Data on health status (surgical method, UICC tumor stage [34], time since diagnosis via punch biopsy, Karnofsky performance status [35], extent of urinary incontinence, comorbidities) and healthcare system (rehabilitation setting) were provided by physicians or retrieved from medical records. Urinary incontinence was clinically assessed by physicians using a study-specific scale ( ${ }^{\circ} 0$ : no leakage, ${ }^{\circ} 1$ : only in the afternoon, ' 2 : already before noon, ' ${ }^{\circ} 3$ : also at night').

Well-being, function and symptoms were assessed using the Hospital Anxiety and Depression Scale (HADS), the European Organization for Research and Treatment of Cancer Quality of Life Questionnaire (EORTC QLQ-C30) and its prostate cancer-specific module (-PR25). The HADS [36] was specifically designed to measure anxiety and depression in somatically ill patients. The instrument consists of two subscales for anxiety and depression, both ranging from 0 to 21 points, with cut-offs of $\geq 11$ indicating clinically relevant symptom levels. The EORTC QLQ-C30 [37] measures health-related quality of life and consists of six functional (global health status; physical, role, social, emotional, cognitive functioning) and 15 symptom scales. The EORTC QLQ-PR25 [38] assesses sexual functioning and four symptom scales (urinary, bowel and hormonal treatment-related symptoms, bother due to use of incontinence aid). All scale scores are linearly transformed to a 0-100 scale, with higher scores reflecting either higher levels of functioning or higher symptom burden.

Factors of work demands and work environment were assessed using the Screening Instrument Work and 
Occupation (German Abbrev.: SIBAR), the Effort-Reward Imbalance at Work Questionnaire (German Abbrev.: ERI) and the Occupational Stress and Coping Inventory (German Abbrev.: AVEM), which are validated self-rating instruments frequently used in the rehabilitation setting to identify patients with work-related problems. The SIBAR [39] provides information on potential risk factors for early retirement: the intention to apply for a disability pension (answers were "yes" vs. "no"), patients' self-perceived work ability (answers were "not being able to work (<3 h/day)", "limited work ability (3-6 hours/day)" and "full work ability ( $>6 \mathrm{~h} /$ day"), patients' self-perceived capacity to return to the former job and related working tasks (answers were "definitely yes", "probably yes", "uncertain", "probably no", "definitely no"), duration of sick leave in the year preceding the rehabilitation program (answers were "no sick leave", "0-5 weeks", "6-25 weeks" and "26 weeks and more"), and feelings of occupational stress (answers were dichotomized into "yes" (="very stressed") vs. "no" (="somewhat stressed" to "job is very fullfilling")). The ERI was applied to measure the amount of effort spent at work and the reward gained in return. Subscale means for effort and reward range from 0 to 5 , with higher values reflecting either higher effort or reward. The ERI-ratio can be calculated to assess the individual's effort-reward imbalance, which is indicated by a score of $\geq 1[40,41]$. The AVEM assesses work behavior in three domains relevant for professional demands and health (work commitment, resistance to stress, emotions). Individuals can be categorized into one of four work-related behavior patterns and coping styles: healthy-ambitious (Type G), unambitious (Type S), excessively ambitious
(Risk Type A) and resigned (Risk Type B) [42]. Questionnaires specifically developed for use in this study are provided as Additional file 1).

\section{Recruitment procedures and nonresponder analysis Recruitment of survivors}

During the study period, 1798 survivors of working age who had been treated for localized prostate cancer by radical prostatectomy were admitted to the participating rehabilitation clinics. Overall, 837 survivors met the inclusion criteria and responded to the first two questionnaires at the beginning and the end of the rehabilitation program. The response rate at 12-months follow-up was $85 \%$ (714 survivors). As three survivors did not report their work status at follow-up, 711 cases were assessable for the presented analyses (Fig. 1).

\section{Nonresponder analyses}

Differences between responders and nonresponders at 12-months follow-up were assessed regarding socio-demographic, disease-specific and psychological characteristics. At the beginning of the rehabilitation program, responders were significantly older (57 vs. 56 years) and more frequently married ( 84 vs. $75 \%$ ) than nonresponders. However, a logistic regression analysis showed that those variables could only explain a small part of the response variation (Nagelkerkes $R^{2}: 0.047$ ).

\section{Statistical analysis}

We performed descriptive analyses to examine study population characteristics and to assess the RTW rate and time until RTW at 12-months follow-up. For

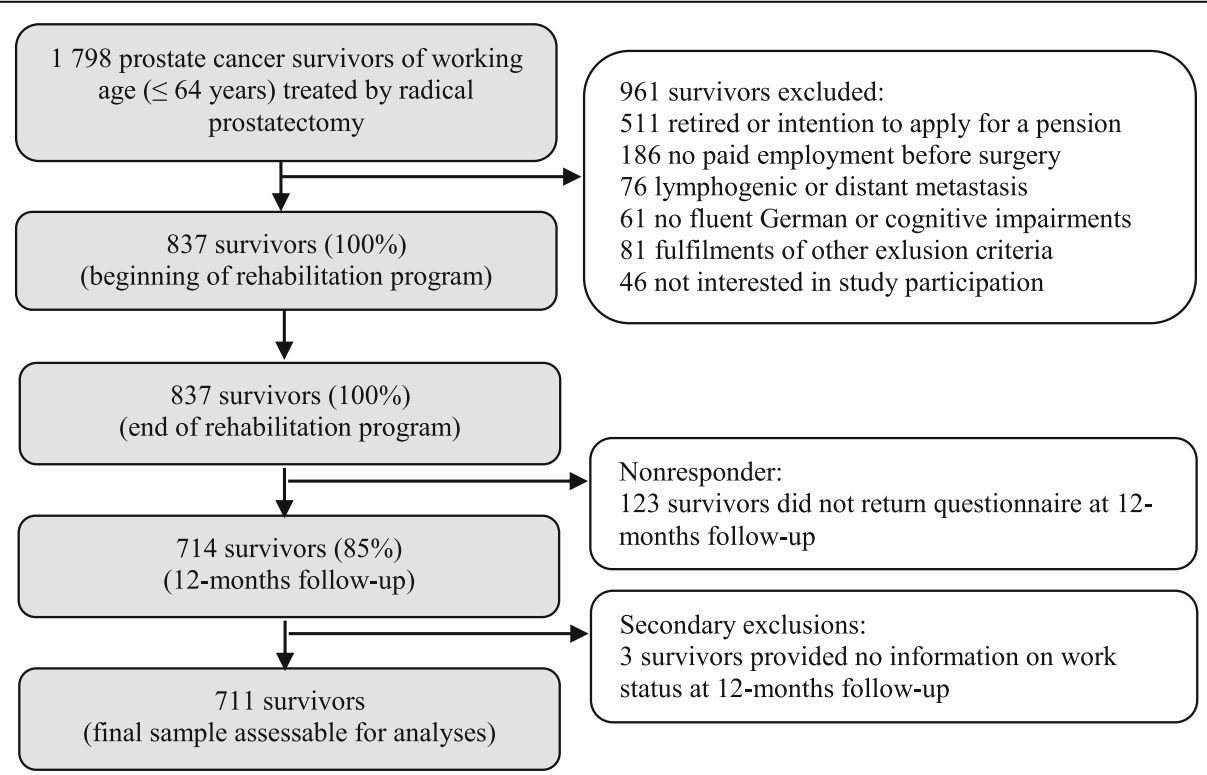

Fig. 1 Flow chart of questionnaire responses 
comparison of baseline characteristics of the survivor groups (returned vs. not returned to work), we conducted univariate analyses using chi-square-tests and two-sample t-tests. Associations between potential predictor variables and RTW outcomes at follow-up were analyzed using multivariate logistic regression models with no RTW and late RTW ( $\geq 8$ weeks) being the dependent variables. Survivors who had returned to work and those with early RTW $(<8$ weeks) were classified as reference groups, respectively. Therefore, potential predictors - including all variables that revealed significant group differences in the univariate analyses - were tested for correlation and multicollinearity (spearman's coefficient rho $\geq 0.6$, tolerance values $\leq 0.6$ ). Based on the approach of theoretical and statistical pre-selection of variables, all remaining potential predictors were entered simultaneously into the regression analyses (method: enter). Missing data was handled by list-wise deletion and the strengths of associations were expressed as odds ratios (OR) with 95\% confidence intervals (CI). All significance tests were two-tailed using a significance level of $\alpha<.05$. Analyses were performed using SPSS software version 18.0.

\section{Results}

\section{Study population characteristics}

Of 711 survivors, $84 \%$ were married, $47 \%$ low-educated, and the mean age was 57 years (range: 40-64). On average, survivors had been diagnosed with prostate cancer approximately 3 months prior to the program, with UICC tumor stage II being most prevalent. Fifty-two percent had been treated with open radical prostatectomy and $48 \%$ with laparoscopic or robotic approaches (Table 1).

\section{RTW rate at 12-months follow-up}

Sixhundred-eighteen survivors $(87 \%)$ had returned to work. Reasons for not working were being on sick leave in 23 cases, being unemployed in 21, receiving retirement pension in 30, and disability pension in 19 (data not shown). Univariate analyses showed significant group differences between survivors who had vs. had not returned to work regarding socio-demographic and disease-related characteristics, psychosocial well-being and work-related factors, with the latter being the most affected dimension (Tables 2 and 3).

\section{Time until RTW following the cancer rehabilitation program}

Among 618 survivors who had returned to work, the exact date of RTW was not available in 69, leaving 549 for the analysis of time until RTW. Survivors returned to work with a median time of 56 days (mean 73.7, standard deviation 70.6, range: 0-365). Figure 2 depicts descriptive
Table 1 Characteristics of the responders at the beginning of the cancer rehabilitation program $(N=711)$

\begin{tabular}{|c|c|}
\hline & $\begin{array}{l}\text { Whole sample } \\
N=711\end{array}$ \\
\hline Age, M (SD) & $57.0(4.4)$ \\
\hline \multicolumn{2}{|l|}{ Age groups, $n(\%)$} \\
\hline Up to 60 years & $555(66.3)$ \\
\hline 60 years and older & $282(33.7)$ \\
\hline \multicolumn{2}{|l|}{ Family status, $n(\%)$} \\
\hline Married & $591(83.8)$ \\
\hline Single & $44(6.2)$ \\
\hline Separated, divorced or widowed & $70(9.9)$ \\
\hline \multicolumn{2}{|l|}{ Educational level, $n(\%)$} \\
\hline Up to 9 years & $324(46.9)$ \\
\hline 10 years & $156(22.6)$ \\
\hline $12-13$ years & $211(30.5)$ \\
\hline \multicolumn{2}{|l|}{ Work status, n (\%) } \\
\hline Full-time & $663(95.9)$ \\
\hline Part-time & $28(4.1)$ \\
\hline \multicolumn{2}{|l|}{ Type of occupation, $n(\%)$} \\
\hline Blue-collar job & $247(35.1)$ \\
\hline White-collar job & $352(50.1)$ \\
\hline Self-employed or public servant & $104(14.8)$ \\
\hline \multicolumn{2}{|l|}{ Monthly household net income, $n(\%)$} \\
\hline$<2000 €$ & $136(20.0)$ \\
\hline $2000-<3000 €$ & $237(34.9)$ \\
\hline $3000-<4000 €$ & $187(27.5)$ \\
\hline $4000 €$ or more & $119(17.5)$ \\
\hline \multicolumn{2}{|l|}{ Tumor stage at diagnosis (UICC),$n(\%)$} \\
\hline Stage I & $82(11.5)$ \\
\hline Stage II & $480(67.6)$ \\
\hline Stage III & $148(20.8)$ \\
\hline Time since diagnosis (in months) ${ }^{b}, M(S D)$ & $2.8(5.0)$ \\
\hline \multicolumn{2}{|l|}{ Number of comorbid conditions } \\
\hline None & $279(39.2)$ \\
\hline 1 & $254(35.7)$ \\
\hline 2 or more & $178(25.0)$ \\
\hline \multicolumn{2}{|c|}{ Surgical procedure (radical prostatectomy), n (\%) } \\
\hline Open (retropubic or perineal) & $369(51.9)$ \\
\hline Laparoscopic & $95(13.4)$ \\
\hline Robot-assisted (DaVinci) & $247(34.7)$ \\
\hline
\end{tabular}

data on the days patients needed to return to work after the end of rehabilitation $(100 \%=549$ survivors having returned to work within 1 year following the program). 
Table 2 Socio-demographic and disease-specific characteristics of prostate cancer survivors at the beginning of the cancer rehabilitation program with regard to work status at 12-months follow-up $(N=711)$

\begin{tabular}{|c|c|c|c|c|c|c|c|c|c|}
\hline & \multicolumn{4}{|c|}{$\begin{array}{l}\text { Not returned to work } 12 \text { months after } \\
\text { the end of the rehabilitation program } \\
N=93\end{array}$} & \multicolumn{4}{|c|}{$\begin{array}{l}\text { Returned to work } 12 \text { months after } \\
\text { the end of the rehabilitation program } \\
N=618\end{array}$} & \multirow[b]{2}{*}{$p$-value } \\
\hline & $\mathrm{n}$ & $\%$ & M & SD & $\mathrm{n}$ & $\%$ & M & SD & \\
\hline \multicolumn{10}{|l|}{ Socio-demographic characteristics } \\
\hline Age & 93 & & 59.7 & 3.2 & 618 & & 56.9 & 4.4 & $<.001^{\mathrm{a}}$ \\
\hline \multicolumn{10}{|l|}{ Family status } \\
\hline Married & 77 & 83.7 & & & 514 & 83.8 & & & $.970^{\mathrm{b}}$ \\
\hline Other & 15 & 16.3 & & & 99 & 16.2 & & & \\
\hline \multicolumn{10}{|l|}{ Educational level } \\
\hline Up to 9 years & 45 & 50.6 & & & 279 & 46.3 & & & $.442^{\mathrm{b}}$ \\
\hline 10 years & 22 & 24.7 & & & 134 & 22.3 & & & \\
\hline $12-13$ years & 22 & 24.7 & & & 189 & 31.4 & & & \\
\hline \multicolumn{10}{|l|}{ Occupational status } \\
\hline Blue -collar job & 34 & 37.4 & & & 213 & 34.8 & & & $.369^{\mathrm{b}}$ \\
\hline White -collar job & 40 & 44.0 & & & 312 & 51.0 & & & \\
\hline Self-employed or public servant & 17 & 18.7 & & & 87 & 14.2 & & & \\
\hline \multicolumn{10}{|l|}{ Monthly household net income } \\
\hline$<2000 €$ & 24 & 27.9 & & & 95 & 16.0 & & & $.024^{\mathrm{b}}$ \\
\hline $2000-<4000 €$ & 48 & 55.8 & & & 376 & 63.4 & & & \\
\hline $4000 €$ or more & 14 & 16.3 & & & 122 & 20.6 & & & \\
\hline \multicolumn{10}{|l|}{ Disease-specific characteristics } \\
\hline \multicolumn{10}{|l|}{ Surgical procedure } \\
\hline Open (retropubic or perineal) & 48 & 51.6 & & & 321 & 51.9 & & & $.953^{\mathrm{b}}$ \\
\hline Laparoscopic or robot-assisted (DaVinci) & 45 & 48.4 & & & 297 & 48.1 & & & \\
\hline \multicolumn{10}{|l|}{ UICC tumor stage ${ }^{c}$} \\
\hline Stage | or || & 61 & 65.6 & & & 501 & 81.2 & & & $.001^{b}$ \\
\hline Stage III & 32 & 34.4 & & & 116 & 18.8 & & & \\
\hline $\begin{array}{l}\text { Time since diagnosis (via punch biopsy) } \\
\text { in months }\end{array}$ & 93 & & 3.0 & 6.6 & 618 & & 2.8 & 4.7 & $.665^{\mathrm{a}}$ \\
\hline Karnofsky performance status (0-100\%) & 93 & & 78.5 & 7.7 & 618 & & 79.3 & 8.8 & $.412^{\mathrm{a}}$ \\
\hline \multicolumn{10}{|l|}{ Extent of urinary incontinence } \\
\hline${ }^{\circ} 0$ - no leakage & 7 & 7.5 & & & 90 & 14.6 & & & $.179^{\mathrm{b}}$ \\
\hline${ }^{\circ} 1$ - only in the afternoon & 21 & 22.6 & & & 158 & 25.6 & & & \\
\hline${ }^{\circ} 2$ - already before noon & 23 & 24.7 & & & 140 & 22.7 & & & \\
\hline${ }^{\circ} 3$ - also at night & 42 & 45.2 & & & 228 & 37.0 & & & \\
\hline \multicolumn{10}{|l|}{ Number of comorbid conditions } \\
\hline None & 27 & 29.0 & & & 252 & 40.8 & & & $.053^{\mathrm{b}}$ \\
\hline 1 & 35 & 37.6 & & & 219 & 35.4 & & & \\
\hline 2 or more & 31 & 33.3 & & & 147 & 23.8 & & & \\
\hline \multicolumn{10}{|l|}{ Setting of the cancer rehabilitation program } \\
\hline Inpatient & 82 & 88.2 & & & 535 & 86.6 & & & $.671^{\mathrm{b}}$ \\
\hline Outpatient & 11 & 11.8 & & & 83 & 13.4 & & & \\
\hline
\end{tabular}

Abbreviations $M$ mean, SD Standard deviation, $p$-value, probability of type I error

Significant $p$-values are marked in bold

at-test, two-tailed

${ }^{\mathrm{b}}$ chi-square-test

'UICC International Union against Cancer 
Table 3 Psychosocial and work-related factors of prostate cancer survivors at the beginning of the rehabilitation program with regard to work status at 12 -months follow-up $(N=711)$

\begin{tabular}{|c|c|c|c|c|c|c|c|c|c|}
\hline & \multicolumn{4}{|c|}{$\begin{array}{l}\text { Not returned to work } 12 \text { months after } \\
\text { the end of the rehabilitation program } \\
N=93\end{array}$} & \multicolumn{4}{|c|}{$\begin{array}{l}\text { Returned to work } 12 \text { months after } \\
\text { the end of the rehabilitation program } \\
N=618\end{array}$} & \multirow[b]{2}{*}{$p$-value } \\
\hline & $\bar{n}$ & $\%$ & M & SD & $\bar{n}$ & $\%$ & M & SD & \\
\hline \multicolumn{10}{|l|}{ Psychosocial well-being, function and symptoms } \\
\hline \multicolumn{10}{|l|}{ Anxiety and Depression (HADS) } \\
\hline Anxiety & 93 & & 6.2 & 4.3 & 616 & & 5.6 & 3.8 & $.149^{\mathrm{a}}$ \\
\hline Depression & 93 & & 5.4 & 4.0 & 617 & & 4.8 & 3.4 & $.146^{\mathrm{a}}$ \\
\hline \multicolumn{10}{|l|}{ Quality of Life - functioning (EORTC QLQ-C30) } \\
\hline Global health status/ quality of life & 93 & & 48.1 & 22.4 & 618 & & 53.1 & 20.6 & $.032^{\mathrm{a}}$ \\
\hline Physical functioning & 93 & & 68.2 & 20.9 & 617 & & 72.9 & 19.0 & $.031^{\mathrm{a}}$ \\
\hline Role functioning & 93 & & 37.1 & 31.4 & 615 & & 40.6 & 33.7 & $.350^{\mathrm{a}}$ \\
\hline Emotional functioning & 93 & & 61.0 & 27.8 & 615 & & 64.0 & 24.9 & $.283^{\mathrm{a}}$ \\
\hline Cognitive functioning & 93 & & 77.1 & 26.7 & 616 & & 78.6 & 22.8 & $.547^{\mathrm{a}}$ \\
\hline Social functioning & 93 & & 50.7 & 30.0 & 618 & & 56.1 & 27.7 & $.083^{\mathrm{a}}$ \\
\hline \multicolumn{10}{|l|}{ Quality of life - symptoms (EORTC QLQ-PR25) ${ }^{c}$} \\
\hline Urinary symptoms & 93 & & 48.2 & 19.5 & 615 & & 45.7 & 20.0 & $.265^{\mathrm{a}}$ \\
\hline Bowel symptoms & 92 & & 10.4 & 13.1 & 614 & & 8.3 & 11.4 & $.141^{\mathrm{a}}$ \\
\hline Hormonal treatment-related symptoms & 92 & & 16.0 & 13.3 & 617 & & 14.0 & 12.2 & $.143^{\mathrm{a}}$ \\
\hline Bother due to use of incontinence aid & 73 & & 47.0 & 35.9 & 452 & & 42.1 & 33.5 & $.249^{\mathrm{a}}$ \\
\hline \multicolumn{10}{|l|}{ Work-related issues and behaviors } \\
\hline \multicolumn{10}{|l|}{ Work-related behavior pattern (AVEM) } \\
\hline Healthy ambitious- Type G & 25 & 26.9 & & & 156 & 25.2 & & & $.092^{\mathrm{d}}$ \\
\hline Unambitious- Type S & 37 & 39.8 & & & 196 & 31.7 & & & \\
\hline Excessively unambitious- Risk Type A & 14 & 15.1 & & & 112 & 18.1 & & & \\
\hline Resigned- Risk Type B & 16 & 17.2 & & & 102 & 16.5 & & & \\
\hline Unclear & 1 & 1.1 & & & 52 & 8.4 & & & \\
\hline \multicolumn{10}{|l|}{ Work-related issues (SIBAR) } \\
\hline Self-perceived work ability & & 92 & & & 615 & & & & \\
\hline Not able to work (< $3 \mathrm{~h} /$ day $)$ & & 38 & 41.3 & & 124 & 20.2 & & & $<.001^{\mathrm{d}}$ \\
\hline Limited ability (3-6 h/day) & & 49 & 53.3 & & 415 & 67.5 & & & \\
\hline Full ability (> $6 \mathrm{~h} /$ day) & & 5 & 5.4 & & 76 & 12.4 & & & \\
\hline \multicolumn{10}{|l|}{ Sick leave in the 12 months preceding rehabilitation } \\
\hline None or up to 5 weeks & 55 & 60.4 & & & 499 & 82.3 & & & $<.001^{\mathrm{d}}$ \\
\hline 6 weeks or more & 36 & 39.6 & & & 107 & 17.7 & & & \\
\hline Intention to apply for a disability pension (yes) & 39 & 43.8 & & & 124 & 20.6 & & & $<.001^{\mathrm{d}}$ \\
\hline Occupational stress (yes) & 22 & 24.2 & & & 76 & 12.4 & & & $.002^{\mathrm{d}}$ \\
\hline \multicolumn{10}{|c|}{ Self-perceived capacity to return to the former job and related working tasks } \\
\hline Probably or definitely yes & 55 & 59.1 & & & 532 & 86.6 & & & $<.001^{\mathrm{d}}$ \\
\hline Uncertain & 23 & 24.7 & & & 67 & 10.9 & & & \\
\hline Probably or definitely no & 15 & 16.1 & & & 15 & 2.4 & & & \\
\hline \multicolumn{10}{|l|}{ Effort-reward imbalance (ERI) } \\
\hline Effort $^{\mathrm{e}}$ & 89 & & 16.5 & 5.1 & 614 & & 15.5 & 4.4 & $.094^{\mathrm{a}}$ \\
\hline Reward & 85 & & 46.4 & 7.6 & 591 & & 48.2 & 6.8 & $.022^{\mathrm{a}}$ \\
\hline Effort-reward imbalance (cut off $\geq 1$ ) & 12 & 14.1 & & & 48 & 8.1 & & & $.071^{\mathrm{d}}$ \\
\hline
\end{tabular}

Abbreviations $M$ mean, $S D$ Standard deviation, $p$-value probability of type I error

Significant $p$-values are marked in bold

at-test, two-tailed

${ }^{\mathrm{b}}$ scale $0-100(100 \cong$ maximum level of functioning), symptom scales not included in the presented analyses

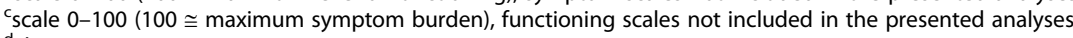

d chi-square-test

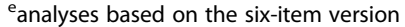




\section{Predictors of not having returned to work at 12-months follow-up}

In the multivariate regression model, older age (OR 1.247), UICC tumor stage III (OR 2.268), sick leave of 6 weeks and more (in the year preceding the rehabilitation program; OR 2.981), patients' self-perceived (baseline) inability to work (OR 3.671), lacking capacity to return to the former job and related working tasks (3.162) and intention to apply for a disability pension (OR 2.214) increased the likelihood for not having returned to work at 12-months follow-up (Table 4). The regression model explained $28 \%$ of the total variance (Nagelkerke's $\mathrm{R}^{2}$ : 0.283).

\section{Predictors of late return to work ( $\geq 8$ weeks) following the cancer rehabilitation program}

In the multivariate regression model, UICC tumor stage III (OR 2.946), and patients' self-perceived (baseline) limited work ability (OR 2.154) and not being able to work (OR 4.502) as well as uncertainty about the capacity to return to the former job and related working tasks (OR 2.876) were significant predictors for late RTW (Table 4). The regression model explained 22\% of the total variance (Nagelkerke's $R^{2}: 0.215$ ).

\section{Discussion}

This prospective multicentre-study analyzed the RTW rate and time until RTW in a cohort of 711 prostate cancer survivors 12 months after having attended a cancer rehabilitation program. Previous international studies demonstrated RTW rates of cancer survivors ranging from 24 to $94 \% 1$ year post diagnosis [5]. Regarding the population of prostate cancer patients, international studies suggest relatively high RTW rates [8, 9, 24]. For example, among working age prostate cancer patients

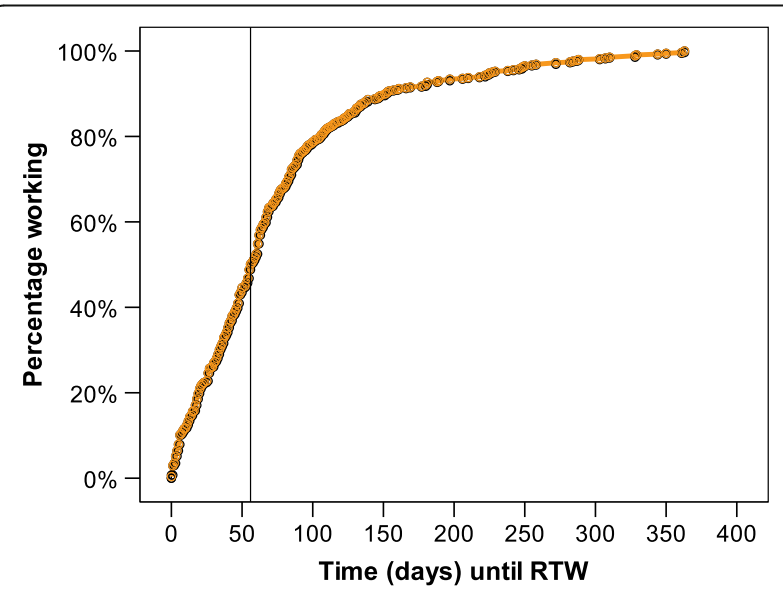

Fig. 2 Return to work (RTW; in days) of prostate cancer survivors within the 12 months following the cancer rehabilitation program $(N=549)$ who had received radiotherapy, $75 \%$ were reported to be available for work 1 year after treatment [43]. In our study, $87 \%$ of survivors had returned to work 12 months after the end of the rehabilitation program. Thus, the RTW rate was higher compared to results from two other studies conducted in the German cancer rehabilitation setting. Both studies analyzed mixed samples (both genders and different cancer types) and revealed RTW rates of 79\% [44] and 76\% [45] by 1 year after the rehabilitation program. However, such comparison of RTW rates has to take into account that in our study, only cancer survivors who were active in the workforce before radical prostatectomy were included.

Overall, prostate cancer patients seem to return to work faster when compared with patient groups diagnosed with other cancer types [46]. In our study, median time until RTW was 56 days, while other studies reported a five-week median time until RTW in urologic (specifically prostate) cancer patients from the U.K. [46] and a median sickness absence of 20 days in U.S. prostate cancer patients [11]. In a study with Norwegian prostate cancer patients who were employed before radical prostatectomy, 51\% had returned to work within 6 weeks and 73\% within 910 weeks post-operative [47]. Comparing robot-assisted laparoscopic to open radical prostatectomy among prostate cancer patients, studies demonstrated a shorter time until RTW (35 vs. 48 days) in Swedish patients [48] and a shorter median sick leave (11 vs. 49 days) in Swedish/Danish patients [49]. In our study, approximately half of survivors had been treated with open prostatectomy. Thus, the median amount of 56 days needed to RTW seems to support findings of these studies.

However, comparability of our data with international studies is limited due to heterogeneous healthcare and/ or social systems as well as the uniqueness of the German rehabilitation system.

Further, we investigated baseline risk factors for not having returned to work at 12-months follow-up and late RTW. Although univariate analyses showed global quality of life and physical functioning to be significantly lower in patients who had not returned to work, those aspects were not relevant in the multivariate analyses. None of the physical symptoms or disease-related lasting effects seemed to have an impact, while reviews focusing on RTW after cancer suggest fatigue and other physical symptoms to be important predictors for RTW outcomes [5, 32]. In prostate cancer patients, constipation was found to predict longer RTW [46] and pre-operative physical health-related quality of life was predictive for declined work status 3 months after radical prostatectomy [47]. 
Table 4 Results of the multivariate regression models of having returned to work and late return to work at 12-months follow-up

\begin{tabular}{|c|c|c|c|c|c|c|c|c|c|c|}
\hline & \multicolumn{10}{|c|}{ Multivariate regression analyses } \\
\hline & \multicolumn{5}{|c|}{$\begin{array}{l}\text { Not returned to work } 12 \text { months after } \\
\text { the end of the rehabilitation program } \\
N=617^{\mathrm{a}}\end{array}$} & \multicolumn{5}{|c|}{$\begin{array}{l}\text { Late return to work ( } \geq 8 \text { weeks) following } \\
\text { the cancer rehabilitation program } \\
N=491^{b}\end{array}$} \\
\hline & $\bar{\beta}$ & SE & $p$-value ${ }^{c}$ & OR & $95 \% \mathrm{Cl}$ & $\bar{\beta}$ & SE & $p$-value ${ }^{c}$ & OR & $95 \% \mathrm{Cl}$ \\
\hline$\overline{\text { Age }}$ & .221 & .046 & $<.001$ & 1.247 & $1.139-1.366$ & .018 & .023 & .452 & 1.018 & $.972-1.066$ \\
\hline \multicolumn{11}{|l|}{ Monthly household net income } \\
\hline $4000 €$ and more & Ref. & & & & & Ref. & & & & \\
\hline $2000-<4000 €$ & -.134 & .379 & .724 & .875 & $.416-1.837$ & .439 & .271 & .106 & 1.552 & $.911-2.641$ \\
\hline$<2000 €$ & .198 & .467 & .671 & 1.219 & $.488-3.043$ & .604 & .373 & .105 & 1.830 & $.881-3.801$ \\
\hline \multicolumn{11}{|l|}{ Tumor stage $\left(\mathrm{UICC}^{\mathrm{d}}\right)$} \\
\hline Stage | or || & Ref. & & & & & Ref. & & & & \\
\hline Stage III & .819 & .315 & .009 & 2.268 & $1.223-4.028$ & 1.080 & .259 & $<.001$ & 2.946 & $1.773-4.894$ \\
\hline Global health status/Quality of life (EORTC QLQ-C30) & -.001 & .008 & .893 & .999 & $.983-1.015$ & -.002 & .006 & .780 & .998 & $.987-1.010$ \\
\hline Physical functioning (EORTC QLQ-C30) & -.003 & .462 & 691 & .997 & $.980-1.013$ & -.009 & .006 & .172 & .991 & $.979-1.004$ \\
\hline \multicolumn{11}{|c|}{ Sick leave in the 12 months preceding rehabilitation (SIBAR) } \\
\hline None or up to 5 weeks & Ref. & & & & & Ref. & & & & \\
\hline 6 weeks or more & 1.092 & .308 & $<.001$ & 2.981 & $1.629-5.456$ & .249 & .266 & .348 & 1.283 & $.762-2.160$ \\
\hline \multicolumn{11}{|l|}{ Self-perceived work ability (SIBAR) } \\
\hline Full ability (> 6 h/day) & Ref. & & & & & Ref. & & & & \\
\hline Limited ability (3-6 h/day) & .305 & .526 & .562 & 1.357 & $.484-3.809$ & .768 & .345 & .026 & 2.154 & $1.095-4.283$ \\
\hline Not able to work (< $3 \mathrm{~h} /$ day) & 1.300 & .589 & .027 & 3.671 & $1.156-11.653$ & 1.505 & .421 & $<.001$ & 4.502 & $1.971-10.284$ \\
\hline \multicolumn{11}{|l|}{ Self-perceived capacity to return to the former job (SIBAR) } \\
\hline Probably or definitely yes & Ref. & & & & & Ref. & & & & \\
\hline Uncertain & .504 & .339 & .206 & 1.656 & $.758-3.618$ & 1.056 & .398 & .008 & 2.876 & $1.319-6.271$ \\
\hline Probably or definitely no & 1.151 & .580 & .047 & 3.162 & $1.014-9.861$ & .896 & .637 & .160 & 2.450 & $.072-8.545$ \\
\hline \multicolumn{11}{|l|}{ Intention to apply for a disability pension (SIBAR) } \\
\hline No & Ref. & & & & & Ref. & & & & \\
\hline Yes & .795 & .312 & .011 & 2.214 & $1.200-4.083$ & .326 & .256 & .219 & 1.385 & $.824-2.328$ \\
\hline \multicolumn{11}{|l|}{ Occupational stress (SIBAR) } \\
\hline No & Ref. & & & & & Ref. & & & & \\
\hline Yes & -.608 & .462 & .189 & .545 & $.220-1.347$ & .249 & .356 & .442 & 1.315 & $.654-2.264$ \\
\hline Reward (ERI) & .001 & .023 & .979 & 1.001 & $.957-1.046$ & -.009 & .017 & .593 & .991 & $.959-1.024$ \\
\hline
\end{tabular}

Abbreviations B unstandardized regression coefficient, SE Standard error, $p$-value Probability of type I error, OR odds ratio for independent variables, CI 95\% confidence interval

Significant $p$-values are marked in bold

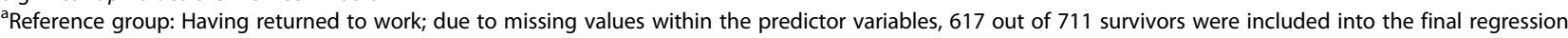
model; tolerance values between $.675-.978$

${ }^{\mathrm{b}}$ Reference group: early return to work ( $<8$ weeks); due to missing values within the predictor variables, 491 out of 549 survivors were included into the final regression model; tolerance values between $.700-.977$

'Wald Test

${ }^{\mathrm{d}}$ UICC International Union against Cancer

Interestingly, the survivors' age was of no significant impact regarding time until RTW. In a study with employed Norwegian prostate cancer patients after radical prostatectomy, age was found to be a risk factor for prolonged sick leave [47]. In our study, as opposed to others [50], the upper age limit was set at 64 years, as the age limit for old age pension in Germany has been raised to up to 67 years and early retirement can cause financial losses or predicaments. Thus, RTW and work-related issues are relevant even in this age group and facilitating RTW within medical rehabilitation programs has been an important point of interest for the German Pension Insurance Agency, reflected by the slogan "rehabilitation before retirement" [25, 27]. 
Consistent with previous studies [44-46], the results of the multivariate logistic regression analyses demonstrate that survivor's perceptions in relation to work impact the RTW process.

In our study, patients' baseline perceptions of no and/ or limited work ability as well as uncertain or no capacity to return to the former job were strong prognostic factors for both not having returned to work at 12-months follow-up and late RTW ( $\geq 8$ weeks). While personal and disease-specific determinants cannot be changed, perceptions about future work might be modifiable during cancer rehabilitation programs. Assessing and responding to adverse perceptions are important goals of occupation-directed interventions in cancer patients [51, 52]. Helping patients to prepare for RTW and to modify maladaptive perceptions through psycho-educational interventions, counseling and advice are core functions of German cancer rehabilitation programs. As was shown in a recent study, an "add-on" structured occupationally oriented rehabilitation program led to better patient ratings of subjective work ability than care as usual [53].

Our results suggest to screen prostate cancer survivors' perceptions in relation to work in order to promote RTW rates and early occupational reintegration. Prospectively, reliable screenings could improve the early and differentiated referral of at-risk survivors to intensified occupational support, both during rehabilitation programs and beyond. In view of evidence-based screening strategies, further research is needed to investigate factors that might increase the probability of not returning to work or prolonged RTW trajectories. Further, in order to organize such support, reasons of survivors' negative perceptions, for example feeling incapable to return to work or their intention to apply for a disability pension, need to be clarified.

Our study has strengths and limitations. In this large-scale longitudinal study, we consecutively collected data from a well-defined population of employed prostate cancer survivors after radical prostatectomy who enrolled in multidisciplinary cancer rehabilitation programs. Reasons for excluding patients from study participation were thoroughly documented. We were able to recruit a large sample size in four specialized German rehabilitation clinics, with a response rate of over $80 \%$ at 12 -months follow-up. Another strength of our study was that we used patient-reported outcomes regarding survivors' work status, psychosocial well-being and work-related factors.

Yet, it is notable, that the results of this study are subject to certain limitations. Among those, the most important was generizability of results. First, our study did not include a control group of rehabilitation non-participants. We cannot assess possible selection bias regarding rehabilitation participants and if RTW outcomes differ between participants and non-participants. Therefore, our results cannot be generalized to non-participants.

Second, half of the patients were treated by open radical prostatectomy, resulting in a strong representation of the respective surgical procedure and associated side effects. Since minimally invasive surgical approaches offer potentially shorter recovery times [54], generizability of the results should be applied with awareness for possible bias in the outcome parameter of time until RTW as well as psychosocial and work-related predictor variables.

Third, early retirement or having applied for a disability pension were used as exclusion criteria (511 patients of the total sample affected), and this might have impacted the results. However, we did not have information on reasons for early retirement or having applied for a disability pension in these patients. Generally, prostate cancer is a disease of older age [13], which may lead to higher early retirement rates in this patient population and may be an aggravating factor in studying RTW as an outcome measure.

Further, our regression model explained a rather moderate ratio of the overall variance in the dependent variable. The regression analyses were aimed at testing predicted factors for not having returned to work and late RTW based on a model of cancer and work proposed by Feuerstein et al. [32]. We acknowledge that there are other important predictors that have a close relationship with RTW and time until RTW that are not considered, leading to the lower amount of variance explained in the regression. However, our study shows that the predicted factors have a significant impact on both outcomes.

Based on the multicentre design, consecutive recruitment strategy, systematic documentation of nonresponders, a high response rate at all times of measurement, and theoretically and statistically derived predictor variables, we consider our results to be valid for employed prostate cancer survivors who participated in a cancer rehabilitation program.

\section{Conclusions}

Next to recovery from physical impairments, the purpose of cancer rehabilitation programs is to improve the individuals' psychological and social functioning, including the ability to return to work. Our findings highlight that RTW in prostate cancer survivors who were active in the working force pre-surgery and attended a cancer rehabilitation program is a realistic goal. Those, who are not able to return to work or who return late seem to be a subgroup of survivors. Results underline the importance of prostate cancer 
survivor's perceptions in relation to work and indicate the need for reliable screening procedures to early identify survivors at risk for adverse RTW outcomes. Those may help to direct the rehabilitation process with regard to intensified occupational support.

\section{Additional file}

Additional file 1: Questionnaires developed specifically for use in this study. (DOCX $16 \mathrm{~kb}$ )

\section{Abbreviations}

AVEM: Occupational Stress and Coping Inventory (German Abbreviation) Cl: Confidence interval; EORTC: European Organization for Research and Treatment of Cancer; ERI: Effort-Reward Imbalance at Work Questionnaire (German Abbreviation); HADS: Hospital Anxiety and Depression Scale; ICF: International Classification of Functioning, Disability and Health; OR: Odds ratio; RTW: Return to work; SIBAR: Screening Instrument Work and Occupation (German Abbreviation); UICC: International Union Against Cancer

\section{Acknowledgments}

General non-financial advisory support has been provided by the COST ACtion IS1211 CANWON (C. Bergelt). We thank all prostate cancer survivors for their effort in participating in the present study.

\section{Funding}

This work was funded by the North Rhine-Westfalia Association for the Fight against Cancer, Germany (no assigned reference number). The funding source was not involved in conduct of the research (collection, analysis and interpretation of the data) and preparation of the article (writing the report, decision to submit the manuscript for publication). The corresponding author had full access to all the data and had responsibility for the decision to submit for publication.

\section{Availability of data and materials}

The authors have full control over the primary data. The data are analyzed in this study are housed at the Department of Medical Psychology, Center for Psychosocial Research, University Medical Center Hamburg-Eppendorf, Martinistrasse 52, 20,246 Hamburg, Germany. As per the research ethics committee approval, this dataset is subject to ethical restrictions and local data protection regulations that do not allow publication of raw data. All relevant data for the conclusions are presented in the manuscript.

\section{Author's contributions}

AU collected data, prepared data for statistical analyses, conducted statistical analyses, searched literature and drafted the manuscript. CB was the principal investigators of the study; she led the application for funding, designed the overall study and supervised data collection, analyses and writing of the manuscript. HMR collected data and prepared data for statistical analyses. UO, CK, MR and CHA recruited patients and collected data. All authors have provided comments and critical revisions. The final manuscript was approved by all authors prior to submission.

\section{Ethics approval and consent to participate}

Ethical committee approval was granted by the General Medical Council of Hamburg, Germany (reference number PV3547, 08 October 2010). The study has been approved by the department of data security of the German Pension Insurance Agency, Berlin, Germany. All study participants provided written informed consent for study participation, data analysis and publication

\section{Consent for publication}

Not applicable.

\section{Competing interests}

The authors declare that they have no competing interests.

\section{Publisher's Note}

Springer Nature remains neutral with regard to jurisdictional claims in published maps and institutional affiliations.

\section{Author details}

'Department of Medical Psychology, University Medical Center Hamburg-Eppendorf, Center for Psychosocial Medicine, Martinistrasse 52, 20246 Hamburg, Germany. ${ }^{2}$ Rehabilitation Clinics Hartenstein GmbH, Clinic Quellental, Bad Wildungen, Germany. ${ }^{3}$ Vivantes Rehabilitation Clinic GmbH, Berlin, Germany. ${ }^{4}$ HELIOS Rehabilitation Clinic Bergisch-Land, Wuppertal, Germany. ${ }^{5}$ Niederrhein Rehabilitation Clinic, Korschenbroich, Germany.

Received: 9 March 2017 Accepted: 20 June 2018

Published online: 20 July 2018

\section{References}

1. Wells M, Williams B, Firnigl D, Lang H, Coyle J, Kroll T, et al. Supporting 'work-related goals' rather than 'return to work' after cancer? A systematic review and meta-synthesis of 25 qualitative studies. Psychooncology. 2012; 22:1208-19.

2. Smedby K. Cancer survivorship and work loss - what are the risks and determinants? Acta Oncol. 2014;53:721-3.

3. Steiner ER, Cavender TA, Main DS, Bradley CJ. Assessing the impact of cancer on work outcomes: what are the research needs? Cancer. 2004;101: 1703-10.

4. van Muijen P, Weevers NL, Snels IA, Duijts SF, Bruinvels DJ, Schellart AJ, et al. Predictors of return to work and employment in cancer survivors: a systematic review. Eur J Cancer Care. 2013;22:144-60.

5. Mehnert A. Employment and work-related issues in cancer survivors. Crit Rev Oncol/Hematol. 2011;77:109-30.

6. De Boer AG, Taskila T, Ojajarvi A, van Dijk FJ, Verbeek JH. Cancer survivors and unemployment: a meta-analysis and meta-regression. JAMA. 2009;301: 753-62.

7. Carlsen $\mathrm{K}$, Oksbjerg Dalton S, Frederiksen K, Diderichsen F, Johansen C. Cancer and the risk for taking early retirement pension: a Danish cohort study. Scand J Public Health. 2008;36:117-25.

8. Roelen CA, Koopmans PC, Schellart AJ, van der Beek AJ. Resuming work after cancer: a prospective study of occupational register data. J Occup Rehabil. 2011:21:431-40.

9. Sultan R, Slova D, Thiel B, Lepor H. Time to return to work and physical activity following open radical retropubic prostatectomy. J Urol. 2006;176: $1420-3$

10. Marino P, Teyssier LS, Malavolti L, Le Corroller-Soriano AG. Sex differences in the return-to-work process of cancer survivors 2 years after diagnosis: results from a large French population-based sample. J Clin Oncol. 2013;31:1277-84.

11. Bradley CJ, Oberst K, Schenk M. Absenteeism from work: the experience of employed breast and prostate cancer patients in the months following diagnosis. Psychooncology. 2006;15:739-47.

12. Jemal A, Bray F, Center MM, Ferlay J, Ward E, Forman D. Global cancer statistics. CA Cancer J Clin. 2011;61:69-90.

13. GLOBOCAN 2012, International Agency for Research on Cancer WHO Europe Region (EURO) - Male estimated incidence by age (Online Analysis). IARC Web site: http://globocan.iarc.fr Accessed 21 Sept 2016

14. Fryers T. Work, identity and health. Clin Pract Epidemiol Ment Health. 2006;2:12.

15. Konrad AM, Ritchie JE Jr, Lieb P, Corrigall E. Sex differences and similarities in job attribute preferences: a meta-analysis. Psychol Bull. 2000;126:593-641.

16. Grunfeld E, Drudge-Coates L, Rixon L, Eaton E, Cooper A. "The only way I know how to live is to work": a qualitative study of work following treatment for prostate cancer. Health Psychol. 2013;32:75-82.

17. Ullrich A, Böttcher HM, Bergelt C. Gender-related aspects of returning to work in cancer survivors. A systematic reviewBundesgesundheitsbl. 2012;55:516-32.

18. Bradley CJ, Neumark D, Luo Z, Bednarek HL, Schenk M. Employment outcomes of men treated for prostate cancer. J Natl Cancer Inst. 2005; 97:958-65.

19. Bradley CJ, Neumark D, Zhehui L, Schenk M. Employment and cancer: findings from a longitudinal study of breast and prostate cancer survivors. Cancer Investig. 2007;25:47-54. 
20. Sjövall K, Attner B, Englund M, Lithman T, Noreen D, Gunnars B, et al. Sickness absence among cancer patients in the pre-diagnostic and post-diagnostic phases of five common forms of cancer. Support Care Cancer. 2012;20:741-7.

21. Oberst K, Bradley CJ, Gardiner JC, Schenk M, Given CW. Work task disability in employed breast and prostate cancer patients. J Cancer Surviv. 2010;4:322-30

22. Lindbohm ML, Taskila T, Kuosma E, Hietanen P, Carlsen K, Gudbergsson S, et al. Work ability of breast, prostate, and testicular cancer in Nordic countries: a NOWCO study. J Cancer Surviv. 2012;6:72-81.

23. Moskowitz M, Todd BL, Feuerstein M. Cancer survivors and work. In: Gatchel RJ, Schultz IZ, editors. Handbook of occupational health and wellness. Berlin: Springer; 2012. p. 131-50.

24. Gunnarsdottir HK, Vidarsdottir H, Rafnsdottir GL, Tryggvadottir L, Olafsdottir EJ, Lindbohm ML. Employment participation and work experience of male cancer survivors: a NOWCO study. Work. 2013;46:385-93.

25. Hellbom M, Bergelt C, Bergenmar M, Gijsen B, Loge JH, Rautalahti M, et al. Cancer rehabilitation: a Nordic and European perspective. Acta Oncol. 2011; 50:179-86.

26. Stucki G, Melvin J. The international classification of functioning, disability and health: a unifying model for the conceptual description of physical and rehabilitation medicine. J Rehab Med. 2007;39:286-92.

27. Gerdes N, Zwingmann C, Jäckel WH. The system of rehabilitation in Germany. In: Jäckel WH, Bengel J, Herdt J, editors. Research in rehabilitation. Stuttgart: Schattauer; 2006. p. 3-19.

28. Bundesarbeitsgemeinschaft für Rehabiliation (BAR). Rahmenempfehlungen zur ambulanten onkologischen Rehabilitation Frankfurt am Main; 2004 Website: https://www.bar-frankfurt.de/fileadmin/dateiliste/publikationen/ empfehlungen/downloads/Rahmenempfehlung_zur_onkologischen_ Rehabilitation.pdf. Accessed 1 Nov 2017.

29. Deutsche Rentenversicherung Bund. KTL-Klassifikation therapeutischer Leistungen in der medizinischen Rehabilitation Berlin; 2015. Website: https://www.deutsche-rentenversicherung.de/Allgemein/de/Inhalt/3_Infos_ fuer_Experten/01_sozialmedizin_forschung/downloads/sozmed/ klassifikationen/dateianhaenge/KTL/ktl_2015_pdf.pdf?_blob= publicationFile\&v=8. Accessed 1 Nov 2017 .

30. Rath HM, Ullrich A, Otto U, Kerschgens C, Raida M, Hagen-Aukamp C, et al. Rehabilitation processes in out- and inpatient rehabilitation after radical prostatectomy. Rehabilitation. 2017:56:248-56.

31. Ullrich A, Rath HM, Otto U, Kerschgens C, Raida M, Hagen-Aukamp C, et al. Outcomes across the return-to-work process in PC survivors attending a rehabilitation measure - results from a prospective study. Support Care Cancer. 2017;25:3007-15.

32. Feuerstein M, Todd BL, Moskowitz MC, Bruns GL, Stoler MR, et al. Work in cancer survivors: a model for practice and research. J Cancer Surviv. 2010;4: 415-37.

33. Winkler J, Stolzenberg H. Social class index in the Federal Health Survey. Gesundheitswesen. 1999;61 Spec No: S178-83

34. Sobin H, Gospodarowicz MK, Wittekind C, editors. TNM Classification of Malignant Tumours. 7th ed. Oxford: Wiley \& Sons Ltd; 2010.

35. Karnofsky DA, Burchenal JH. The clinical evaluation of chemotherapeutic agents in cancer. In: MacLeod CM, editor. Evaluation of chemotherapeutic agents. New York: Columbia University Press; 1949. p. 191-205.

36. Zigmond AS, Snaith RP. The hospital anxiety and depression scale. Acta Psychiatr Scand. 1983;67:361-70.

37. Aaronson NK, Ahmedzai S, Bergman B, Bullinger M, Cull A, Duez NJ, et al. The European Organization for Research and Treatment of Cancer QLQ-C30: a quality-of-life instrument for use in international clinical trials in oncology. J Natl Cancer Inst. 1993;85:365-76.

38. van Andel G, Bottomley A, Fossa SD, Efficace F, Coens C, Guerif S, et al. An international field study of the EORTC QLQ-PR25: a questionnaire for assessing the health-related quality of life of patients with prostate cancer Eur J Cancer. 2008;44:2418-24.

39. Bürger W, Deck R. SIBAR - a short screening instrument for the assessment of need for occupation related treatment in medical rehabilitation. Rehabilitation. 2009:48:211-21.

40. Siegrist J. Adverse health effects of high-effort/low-reward conditions. J Occup Health Psych. 1996;1:27-41.

41. Siegrist J, Starke D, Chandola T, Godin I, Marmot M, Niedhammer I, et al. The measurement of effort-reward imbalance at work: European comparisons. Soc Sci Med. 2004;58:1483-99.
42. Schaarschmidt U, Fischer AW. Coping with professional demands: a new diagnostic approach. In: Kallus KW, Posthumus N, Jimenez P, editors. Current psychological research in Austria. Graz: Akademische Druck- und Verlagsanstalt; 2001. p. 145-9.

43. Sveistrup J, Mortensen OS, Rosenschöld PM, Engelholm SA, Petersen PM. Employment and sick leave in patients with prostate cancer before, during and after radiotherapy. Scand J Urol. 2016;50:164-9.

44. Böttcher H, Steimann M, Ullrich A, Rotsch M, Zurborn KH, Koch U, et al. Work-related predictors of not returning to work after inpatient rehabilitation in cancer patients. Acta Oncol. 2013;52:1067-75.

45. Mehnert A, Koch U. Predictors of employment among cancer survivors after medical rehabilitation - a prospective study. Scand J Work Environ Health. 2012;39:76-87.

46. Cooper AF, Hankins M, Rixon L, Eaton E, Grunfeld EA. Distinct work-related, clinical and psychological factors predict return to work following treatment in four different cancer types. Psychooncology. 2013;22:659-67.

47. Dahl S, Steinsvik E, Dahl A, Loge J, Cvancarova M, Fossa S. Return to work and sick leave after radical prostatectomy: a prospective clinical study. Acta Oncol. 2014;53(6):744-51.

48. Plym A, Flaminia C, Voss M, Holmberg L, Johansson E, Stattin P, et al. Work disability after robot-assisted or open radical prostatectomy: a nationwise, population-based study. Eur Urol. 2016;70:64-71.

49. Hohwu L, Akre O, Pedersen KV, Jonsson M, Nielsen CV, Gustafsson O. Open retropubic prostatectomy versus robot-assisted laparoscopic prostatectomy: a comparison of length of sick leave. Scand J Urol Nephrol. 2009;43:259-64.

50. Spelten ER, Verbeek JHAM, Uitterhoeve ALJ, Ansink AC, van der Lelie J, de Reijke J, et al. Cancer, fatigue and the return of patients to work-a prospective cohort study. Eur J Cancer. 2003;39:1652-7.

51. Macmillan Cancer Support. Making the Shift - Providing specialist work support to People with Cancer; 2013. Website: https:/www.macmillan.org.uk/ documents/getinvolved/campaigns/workingthroughcancer/making-the-shiftspecialist-work-support-for-people-with-cancer.pdf. Accessed 1 Sept 2016.

52. De Boer AGEM, Taskila TK, Tamminga SJ, Feuerstein M, Frings-Dresen MHM, Verbeek JH. Interventions to enhance return-to-work for cancer patients. Cochrane Database Syst Rev. 2015;9 Art. No. CD007569

53. Böttcher HM, Steimann M, Ullrich A, Rotsch M, Zurborn KH, Koch U, et al. Evaluation of a vocationally oriented concept within inpatient oncological rehabilitation. Rehabilitation. 2013;52:329-36.

54. Keyes M, Crook J, Morton G, Vigneault E, Usmani N, MorrisWJ. Treatment options for localized prostate cancer. Can Fam Physician. 2013;69:1269-74.

\section{Ready to submit your research? Choose BMC and benefit from:}

- fast, convenient online submission

- thorough peer review by experienced researchers in your field

- rapid publication on acceptance

- support for research data, including large and complex data types

- gold Open Access which fosters wider collaboration and increased citations

- maximum visibility for your research: over $100 \mathrm{M}$ website views per year

At BMC, research is always in progress.

Learn more biomedcentral.com/submissions 